\title{
PENGEMBANGAN PROTOTIPE KAPAL PENDETEKSI KADAR GAS BELERANG DAN SUHU BERBASIS ARDUINO
}

\author{
Made Sariyati ${ }^{1)}$, Gede Saindra Santyadiputra'), I Made Putrama ${ }^{3)}$ \\ Fakultas Teknik dan Kejuruan, Universitas Pendidikan Ganesha \\ Email: made.sariyati20@gmail.com, gsaindras@undiksha.ac.id, made.putrama@undiksha.ac.id
}

\begin{abstract}
ABSTRAK
Prototipe kapal pendeteksi kadar gas belerang dan suhu berbasi arduino ini bertujuan untuk (1) memudahkan petani tambak dalam mendeteksi kadar gas belerang, suhu dan $\mathrm{pH}$, (2) meringankan beban petani dalam kematian ikan-ikannya. (3) mengetahui respon hasil pengujian prototipe. Model pengembangan yang dilakukan dalam penelitian ini adalah model prototyping. Pengembangan prototipe ini meliputi pemilihan kebutuhan, membangun prototipe, pengkodean sistem, pengujian sistem dan evaluasi sistem. Penelitian ini diimplementasikan dalam bentuk prototipe alat pendeteksi kadar gas belerang dan suhu, prototipe ini nantinya akan di control menggunakan remote. Untuk proses pengujian, dilakukan (4) tahap pengujian yaitu: (1) pengujian efektivitas, hasil yang didapatkan menyatakan bahwa tingkat efektivitas prototipe mendapatkan persentase sebesar $100 \%$ dengan kategori sangat efektif. (2) uji kepraktisan, diproleh hasil sebesar $96 \%$ responden menyatakan prototipe kapal pendeteksi kadar gas belerang dan suhu ini sangat praktis, (3) uji ahli media diperoleh hasil keseluruhan $93,33 \%$ menyatakan prototipe kapal pendeteksi kadar gas belerang dan suhu ini dinyatakan layak untuk digunakan dan yang terakhir (4) uji ahli isi diperoleh hasil keseluruhan $89,66 \%$ menyatakan prototipe kapal pendeteksi kadar gas belerang dan suhu ini dinyatakan layak untuk digunakan dan yang terakhir (4) uji ahli isi diperoleh hasil keseluruhan $89,66 \%$.
\end{abstract}

Katakunci: Model Prototyping, remote control, kadar gas belerang.

\begin{abstract}
Prototype Development Of Sulfur Gas Levels And Temperature Detector Arduino Based Ship (1) make it easy for pond farmers to detect sulfur gas levels, temperature and $\mathrm{pH}$,(2) reducing the burden on farmers in the death of their fish.(3) knowing the response to the results of testing the prototype. The development model carried out in this study is a prototyping model. Development of this prototype includes selection of requirements, building prototypes, coding systems, system testing and system evaluation. This research was implemented in the form of a prototype. this prototype will be controlled using the remote.For the testing process, there are 4 stages of testing, namely: (1) effectiveness testing, the results obtained state that the level of effectiveness of the prototype gets a percentage of $100 \%$ in the very effective category.(2) practicality test, obtained by the results of $96 \%$ of respondents stated that the prototype of the sulfur gas level detection vessel and temperature is very practical,(3) media expert test obtained an overall result of 93.33\% stating that the prototype of the sulfur gas level detection vessel and this temperature was declared feasible to use and the last (4) content expert test showed an overall result of $89.66 \%$ stating a sulfur gas level detection vessel and this temperature was declared feasible to use and the last (4) content expert test obtained overall results of $89.66 \%$.
\end{abstract}

Keywords: Prototype, remote control, levels of sulfur gas 


\section{PENDAHULUAN}

Perairan danau pada umunya berfungsi sebagai pemasok air permukaan, daerah penyangga, tangkapan resapan air, juga sebagai tempat budi daya perikanan, aktivitas olahraga dan objek daya tarik wisata. Namun dalam perjalanannya, hampir semua danau memiliki masalah. Seperti kawasan wisata dan sumberdaya perairan yang lain pembangunan infrastukur dan pemanfaatan perairan danau untuk kegiatan perikanan akan mempengaruhi kelangsungan dan kelestarian perairan danau [1]

Permasalahan utama yang terjadi di danau adalah tidak mempunyai outlet, pencemaran bahan organic dari akumulasi limbah penduduk serta pencemaran organic yang berasal dari limbah pemupukan pada lahan perkebunan, hortikultur dan sayur-sayuran. Permasalahan lain yang cukup potensial menimbulkan kematian ikan secara masal adalah akumulasi unsur belerang pada perairan danau yang berasal dari aktivitas gunung. Terjadinya kematian ikan masal tersebut membuat para petani mengalami kerugian yang besar, yang dimana tidak ikan yang besar saja mengalami kematian tetapi ikan yang kecilkecil belum siap untuk dipanen pun mengalami kematian juga. Kematian massal ikan merupakan akibat dari proses kompleks sebagai dampak dari akumulasi bahan organic baik pada dasar perairan maupun kolom air. Kematian massal ikan merupakan akibat dari proses kompleks sebagai dampak dari akumulasi bahan organic baik pada dasar perairan maupun kolom air. Pada tahap awal akibat pemupukan bahan organic di dasar perairan adalah pembentukan lapisan anaerobic yang makin besar[2]

Biota air biasa kerancuan (kehilangan keseimbangan) pada konsentrasi $\mathrm{H}_{2} \mathrm{~S} 0,1-0,2 \mathrm{mg} / \mathrm{l}$ (ppm) dan pada konsentrasi $0,25 \mathrm{mg} / \mathrm{l}$ kematian massal biasanya terjadi. Oleh karena itu, konsentrasi asam belerang bagi biota budi daya adalah kurang dari $0,1 \mathrm{mg} /[3]$. Penurunan kualitas air disebabkan oleh banyak factor dan ada beberapa parameter air yang perlu mendapat pengelolaan. Menurut (Ghufran,2010) [4]. Untuk mengatasi masalah tersebut maka dibutuhkan sebuah teknologi. Teknologi yang dibutuhkan untuk mendeteksi kadar belerang yang ada pada danau adalah teknologi yang mampu mengetahui dan mengontrol sistem.

Sebelum mengimplementasikan langsung teknologi yang akan digunakan untuk mendeteksi kadar belerang yang ada maka diperlukan sebuah prototipe. Prototipe berfungsi untuk mengimplementasikan kondisi di lapangan ke dalam bentuk purwa rupa [5].

Selain itu dengan prototipe memudahkan dalam proses pengembangan. Pada penelitian ini peneliti membuat sebuah prototype berupa kapal RC boat yang dimana kapal tersebut membawa sensor-sensor untuk mendeteksi kadar belerang yang ada pada danau, kapal tersebut nantinya akan dikendalikan dengan menggunakan remote control. Sensor-sensor yang digunakan pada penelitian ini ada 3 yaitu, sensor gas MQ-135 untuk mendeteksi kadar gas belerang yang berada pada danau, kemudian ada sensor suhu DS18B20 untuk mencatat suhu yang berada pada air danau dan yang terakhir yaitu sensor $\mathrm{pH}$ (keasaman) untuk mendeteksi kadar keasaman pada air danau. Prototype tersebut nantinya akan dikendalikan menggunakan remote control. Setelah mencatat hasil yang didapat maka data-data tersebut akan tersimpan pada datalogger yang akan diletakkan pada bagian kapal tersebut, maka nantinya hasil dari pendeteksi tersebut akan berupa sebuah data yang sudah diolah secara real time.

Berdasarkan hasil wawancara dengan ahli dan petani ikan, peneliti tertarik melakukan pengembangan menggunakan mikrokontroler arduino.Kelebihan Arduino dibandingkan dengan perangkat mikrokontroler lainya adalah karna arduino bersifat open sources, library yang cukup lengkap, memiliki banyak modul yang siap pakai dan pemrogramannya relative lebih mudah [6]

Kontribusi peneliti dalam pengembangan prototipe pendeteksi kadar gas belereng dan suhu berbasis arduino ini adalah perangkat dapat melakukan aksi untuk mencatat suhu, kadar gas (oksigen), dan kadar keasaman $(\mathrm{pH})$ kemudian data yang diperoleh dapat disimpan pada datalogger yang nantinya hasil dari data tersebut berupa data yang sudah diolah,selain itu data yang dihasilkan akan sudah tertera waktu dan tanggal pendeteksian. Hasil yang diharapkan dari pengembangan prototipe ini petani lebih mudah mengetahui tanda-tanda akan munculnya belerang dipermukaan danau dan mempermudah dalam menangani ikan-ikan ditambak sehingga penanganan menjadi tidak terlambat dan sesuai dengan apa yang diharapkan petani tambak.

\section{METODE}

Pada metode ini guna cara pengumpulan data dan informasi sebagai bahan yang mendukung keberhasilan hasil Selain itu untuk menyelesaikan masalah yang ada dalam sebuah analisis, tahapan, dan perancangan sistem, maka diperlukan beberapa tahap yang harus dilakukan. Metode penelitian bertujuan untuk mengetahui sistematika proses yang berjalan pada pembuatan penulisan. Adapun Kerangka penelitian bisa dilihat pada gambar berikut : 


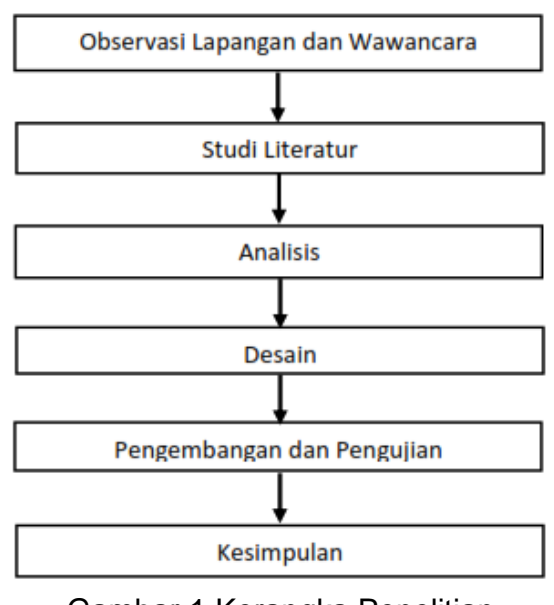

Gambar.1 Kerangka Penelitian

\section{a. Observasi lapangan dan wawancara}

Pada observasi ini meliputi mengamati petani dalam menangani proses kadar belerang, dalam proses tersebut ditemukan bahwa petani kesulitan dalam mendeteksi kadar belerang yang ada pada permukaan danau. Adapun indikator penting dalam pendeteksian kadar belerang adalah suhu dan kadar gas belerang Hasil dari observasi ditemukan bahwa petani tambak mengalami kesulitan dalam mendeteksi adanya kadar belerang yang mengakibatkan matinya ikan-ikan yang ada ditambak tersebut. Berdasarkan hasil wawancara tersebut didapatkan hasil bahwa perubahan kualitas air danau disebabkan oleh beberapa faktor salah satunya cuaca dan pencemaran pada danau. Ketika perubahan musim dan cuaca makan air danau akan mengalami perubahan yang dimana akan mucul belerang yang mengakibatkan ikan-ikan mati begitu saja. Adanya kadar belerang tersebut disebabkan karena adanya bakteri beracun yang mengkibatkan ikan mati dan berbau tidak sedap serta perubahan pada air danau.Setelah mengetahui hasil dari observasi dan wawancara selanjutnya dilakukan analisis untuk membuat suatu solusi terhadap proses permasalahan serta menentukan rancangan pengembangan sistem yang akan dibangun agar sesuai dengan yang diharapan.

\section{b. Studi Literatur}

Tahap ini dilakukan studi literature dengan cara manual yaitu dengan cara mempelajari hasil penelitian dan artikel yang berhubungan dengan konsep analisis dan perancangan dengan menggunakan system serta programan pada mikrokontroler. Ditemukan tiga jurnal sejanis yang berkaitan dengan penelitian ini, dari 3 jurnal tersebut diambil beberapa kesimpulan seperti mikrokontroler yang dipakai, tolak ukur pengujian, kelebihan, dan kekurangan penelitian dan sebagainnya. Perangkat telah dikembangkan oleh Penelitian terkait dikembangkan Riyan Kurniawan Putra (2017) [7]. Analisis Penelitian selanjutnya dilakukan oleh Lukman, Sutrisno \& Agus Hamdani (2013). Perangkat tersebut memantau suhu, oksigen terlarut, dan kadar bahan organic. Parameter penunjang yang diukur adalah tingkat kecerahan dan kadar klorofil dari strata kedalaman, kemudian suhu air diukur menggunakan Van Dorn Sampler, lalu analiasis dilakukan dengan pengambilan contoh air yang kemudian disimpan di dalam botol dan di berikan pengawet asam. Hal ini belum efektif karena penelitian ini dilakukan masih sangat manual tanpa bantuan sensor lainya [8]. Selain itu penelitian juga dilakukan oleh Pengembangan perangkat juga dikembangkan oleh Yoga Eka Saputra (2014) [9] [8] Perangkat tersebut memakai 2 paremeter utama yang diamati yaitu $\mathrm{pH}$ dan suhu, yang dimana kualitas air minum mempunyai $\mathrm{pH}$ antara 6,5 - 8,5 (merupakan batas minimum dan maksimunya) dan perairan dengan $\mathrm{pH}<4$ merupakan perairan yang sangat asam dan dapat menyebabkan kematian makhluk hidup, dan jika $\mathrm{pH}$ $>9,5$ merupakan perairan yang sangat basa yang dapat menyebabkan kematian dan mengurangi produktivitas perairan. Jadi pada penelitian ini fungsinya untuk dapat melacak setiap jenis gerakan apakah panas,tekanan,cahaya atau getaran di daerah tertentu. Adapun yang menjadi acuan dari pengembangan yang akan dilakukan adalah perototipe yang akan dikembangkan mengacu pada 3 indikator yaitu gas, suhu, dan $\mathrm{pH}$. Selain itu untuk menangani terjadinya perubahan pada ketiga indikator tersebut maka dibuatkan sebuah alat yang nantinya dapat mengatur agar indikator tetap pada standar yang sudah ditentukan. Selain itu, 
untuk memudahkan petani tambak dalam mengetahui data yang sudah direkam atau dicatat maka peneliti akan menambahkan sebuah alat berupa data logger yang nantinya hasil dari data tersubut akan tampil berupa data olahan yang nantinya juga akan dapat memunculkan waktu dan tanggal pendeteksian.

\section{c. Analisis}

Analisis yang dilakukan pada penelitian ini yaitu kebutuhan fungsional dan non fungsional yang akan dikembangkan. Berikut adalah kebutuhan non fungsional dari prototype yang akan dibuat.

\section{Business Life}

Untuk menjaga kenyaman dan kemudahan dalam menggunakan alat yang akan dirancang, maka akan selalu melakukan pengupdatetan alat yang dirancang agar dapat lebih canggih lagi dari yang sebelumnya, hal ini dimaksudkan untuk menjaga kualitas dari alat yang akan di rancang.

\section{Performance}

Alat ini akan dapat meringankan beban petani tambak, sebab dengan adanya alat ini maka pendapatan hasil tambak ikan petani akan dapat meningkat dari sebelumnya. Alat ini akan dapat berfungsi dengan baik dan akan memberikan data yang akurat disetiap pemantauannya. Dengan adanya alat ini juga petani tambak tidak perlu khawatir dengan adanya kadar belerang yang bermunculan secara tiba-tiba,sebab dengan menggunakan alat ini kita akan mengetahui langsung seberapa banyaknya kadar belerang yang ada dipermukaan air danau nantinya. Dan alat ini akan sangat memudahkan dan meringankan beban petani tambak nantinya.

Selain menjelaskan kebutuhan non-fungsional,pengembangan prototype kapal pendeteksi kadar gas belerang dan suhu berbasis arduino juga melakukan kebutuhan fungsional antara lain :

a. System yang dibuat harus bisa menampilkan kadar gas dalam milliliter, suhu dalam celcius dan kadar keasaman $(\mathrm{pH})$ dalam derajat celcius dan mempunyai tombol pengaturan input yang berfungsi untuk memberikan masukan yang akan menghasilkan perubahan luaran (output).

b. System yang dibuat harus bisa menjalankan aksinya terhadap kondisi suhu, kadar gas dan kadar keasaman $(\mathrm{pH})$ yang berada dilapangan nantinya,yang dimana akan dapat menghasilkan suatu inputan yang menghasilkan suatu kondisi saat itu.

c. System yang dibuat harus bisa menampilkan catatan hasil dari pemantauan yang telah didapatkan dan hasil tersebut dapat ditampilkan kedalam data logger.

d. System yang dibuat harus bisa menyimpan hasil dari data yang diperoleh kedalam memori card yang nantinya akan menghasilkan data berupa modul.

e. System yang dibuat harus bisa mengapung dan berlayar dengan seimbang ketika berada diatas air yang dimana nantinya akan diperintahkan menggunakan remote control.

\section{d. Desain}

Pada tahap desain desain yang akan dibuat adalah sebagai beikut:

\section{A. Desain Rangkaian Alat Pada Kapal dan Remot}

Desain rangkaian elektronika dari hasil analisis yang sudah dilakukan. Fungsi dari desain rangkaian alat ini diperlukan sebagai panduan atau petunjuk dalam proses pembuatan rangkaian elektronika yang dikembangkan sehingga memudahkan dalam proses pengembangan prototipe.

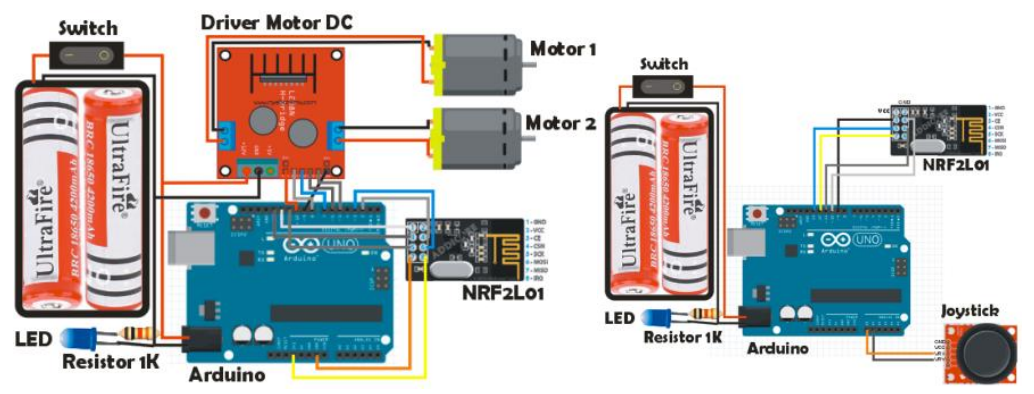


Pada gambar.2 menjelaskan bahwa batterai sebagai arus listrik yang memberikan aliran energy ke switch agar dapat dinyalakan, resistor sebagai penahan arus ke LED yang nantinya agar LED bisa nyal/hidup ketika switch di on kan nantinya, LED ini berfungsi sebagai lampu penanda bahwa prototype yang digunakan sudah hidup, arduino sebagai pengendali dalam system control, NRF24L01 yang berfungsi sebagai komunikasi jarak jauh atau nirkabel yang nantinya akan meberikan dan menerima sinyal dan yang terakhir joystick sebagai pengarah arah gerak kapal maju, kiri, dan kanan.

\section{B. Desain Prototipe Kapal RC Boat dan Desain Remot}

Setelah proses desain rangkaian alat selesai, selanjutnya yaitu proses desain kapal RC boat dan desain remotenya. Fungsi dari desain ini untuk memberikan gagasan tentang bagaimana cara kerja, membantu mengindentifikasi masalah dari desain. Selain itu, dapat menguji berbagai aspek yang ingin dicoba. Berikut adalah desain dari kapal RC boat :

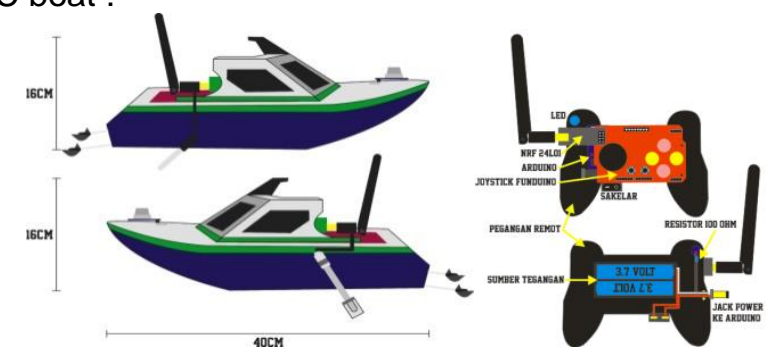

Gambar 3 desain prototipe kapal dan remote

desain prototipe kapal pendeteksi kadar gas belerang dan suhu dan desain pada remote yang digunakan nantinya. Desain tersebut adalah kerangka prototipe yang akan dibuat. Terdapat beberapa komponen dalam prototipe seperti unit mikrokontroler, sensor-sensor, batterai, motor DC dll. Disini juga menjelaskan kelebihan dari prototype yang dibuat ini bisa berlayar mengelilingi danau nantinya untuk mendeteksi kadar gas belerang dan suhu yang ada pada danau dibandingkan dengan alata tradisional sebelumnya yang hanya mendeteksi kadar belerang mengunakan alat seadanya dan harus dilakukan secara berpindah-pindah. Panjang keseluruhan prototype kapal rc boat ini sekitar $40 \mathrm{~cm}$ dengan tinggi $16 \mathrm{~cm}$, yang dimana prototype ini dapat bertahan pada iklim atau cuaca yang buruk disekitar danau, karena pada prototype ini dilindungi oleh pelapis yang sudah didesain sedemikian rupa dan juga alat-alat yang digunakan cukup tahan air. Kecepatan pada prototype ini sedang tidak terlalu cepat dan tidak terlalu lambat sebab pada prototype ini digunakan hanya untuk mendeteksi kadar gas belerang dan suhu yang ada disekitar danau bukan sebagai prototype kapal RC boat yang dilombakan untuk mengukur kecepatan laju kapal. Battrai yang digunakan pada prototype ini cukup tahan lama sekitar 3jam-4jam dan jika sudah habis bisa diisi daya kembali. Pengaruh positif pada penggunaan alat ini yaitu memudahkan petani tambak untuk mengetahui akan adanya bahaya belerang yang akan muncul disekitaran danau, sehingga para petani tambak dapat segera menangani ikan-ikan yang berada pada keranjang jaring apung mereka. Dan untuk pengaruh negative pada alat ini mungkin belum ada karena alat ini dibuat untuk memenuhi kebutuhan petani tambak yang ada disekitaran danau. Disini juga terdapat desain dari remote yang digunakan untuk mengontrol kapal yang nantinya agar bisa berlayar atau bergerak sesuai dengan arah yang kita inginkan, selain itu pada kapal tersebut juga dipasangkan sebuah memori card berupa datalogger yang digunakan menyimpan inputan dari data yang sudah didapatkan.

\section{Flowchart}

Fungsi dari dibuatnya flowchart untuk menggambarkan proses-proses produksi sehingga mudah dipahami dan mudah dilihat berdasarkan urutan langkah dari suatu proses ke proses lainnya. Selain itu juga untuk menyederhanakan proses atau prosedur untuk memudahkan pemahaman pengguna terhadap informasi tersebut. Berikut adalah 
flowchart dari pengembangan prototipe pendeteksi kadar gas belerang dan suhu berbasis arduino.

Flowchat Pada Remote Control:

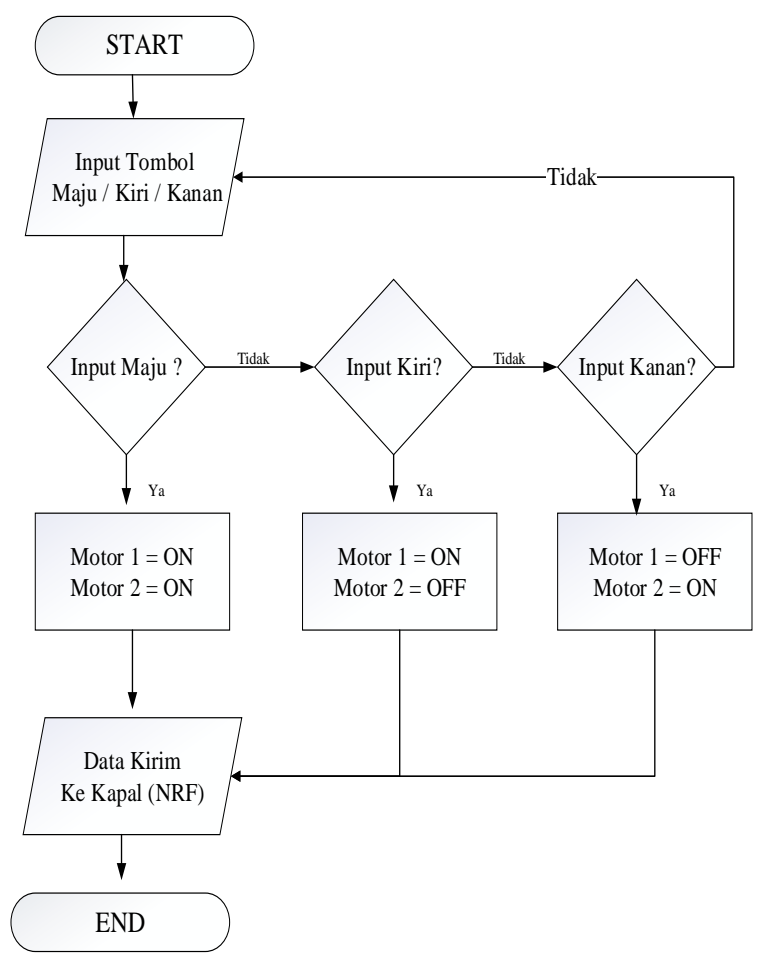

Gambar.4 Flowchat Pada Remote Control

Gambar. 4 menjelaskan diagram alir dari remote control yang dimana pertama data inputan sebelumnya dari kapal Ialu kita pilih tombol pengarah jika memilih maju maka motor 1 on motor 2 on dan bergerak maju secara bersamaan jika tidak memilih maju dan memilih mudur maka motor 1 on motor 2 on dan bergerak berlawanan arah,jikan tidak memilih maju dan memilih kekiri maka motor 1 on dan motor 2 off maka kapal akan bergerak ke kiri dan jikan tidak memilih kekiri dan memilih kekanan makan motor 1 off dan motor 2 on dan kapal akan bergerak kekanan, dan jika tidak memilih kekanan dan tidak memilih tombol pengarah maka tidak akan menggulangi lagi pilihan yang sebelumnya setelah itu maka akan dikirim kekapal dan NRF akan menerima inputan dari remote control.

\section{Flowchat Arduino Kapal:}

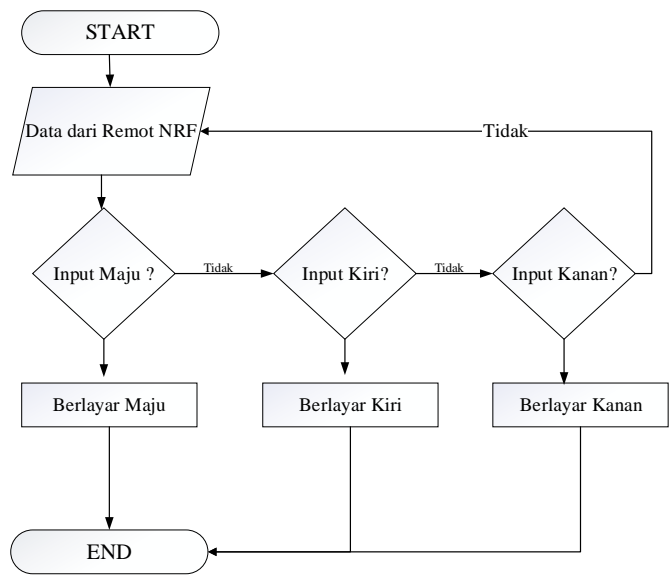

Gambar. 5 Flowchart Prototipe pada kapal 
Gambar.6 menjelaskan diagram alir dari kapal RC boat yang dimana data dari remote yang sudah dikirimkan akan menerima inputan atau masukan maju maka kapal akan berlayar atau bergerak maju jika tidak maju dan memilih inputan kekiri maka kapal berlayar atau bergerak kekiri jika tidak memilih inputan kiri dan memilih inputan kanan maka kapal akan berlayar dan bergerak kekanan dan jika tidak memilih inputan maju, kiri, dan kanan maka data dari remote tidak akan bisa berjalan.

\section{Flowchat Sensor dan Data Logger}

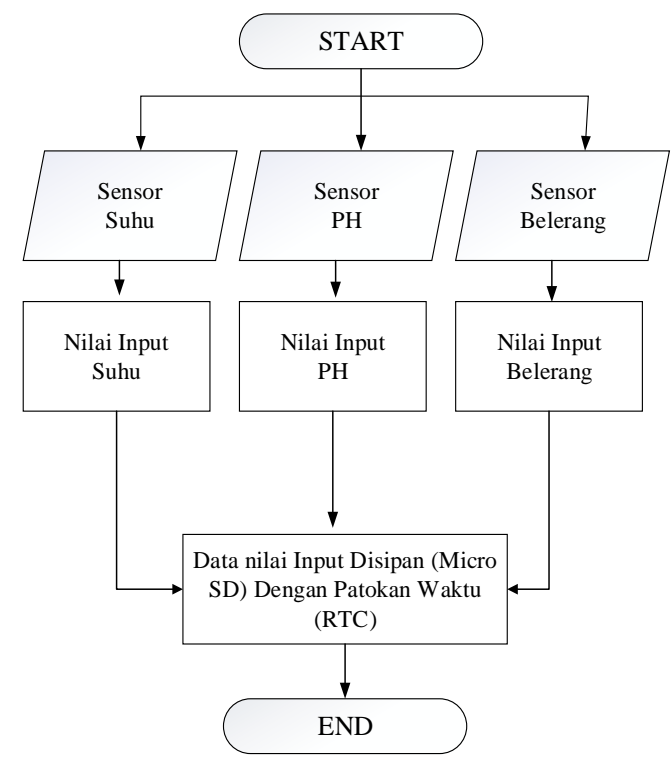

Gambar. 6 Flowchart Sensor dan Data Logger

Gambar. 6 menjelaskan diagram alir dari kapal RC Boat yang pertama kali mendeteksi yaitu sensor suhu, sensor suhu nantinya mendeteksi suhu permukaan air yang nantinya akan mendapatkan nilai masukan dari sensor suhu tersebut, setelah itu sensor $\mathrm{pH}$ akan mendeteksi kadar $\mathrm{pH}$ yang ada di air, yang nantinya akan mendapatkan nilai masukakn dari sensor $\mathrm{pH}$ tersebut, dan yang terakhir sensor kadar gas belerang yang dimana akan mendeteksi kadar gas belerang yang berbahaya yang ada dipermukaan air nantinya, setelah mendeteksi maka akan mendapatkan nilai masukan dari sensor gas tersebut. dari ke 3 sensor tersebut nilai inputannya akan di simpan di micro SD dengan patokan waktu (RTC).

\section{e. Pengembangan dan pengujian}

Pada tahap pengembangan yang dilakukan adalah (a). Pemilihan kebutuhan Pada tahap pengumpulan kebutuhan protoipe maka dilakukan observasi dilapangan, guna mengetahui apa saja yang sebenarnya dibutuhkan dalam proses mendeteksi kadar gas belerang dan suhu tersebut. Setelah mengetahui kebutuhan apa saja yang diperlukan, kemudian melakukan pencaraian data-data dan referensi tentang bagaimana merancang suatu prototype alat untuk mendeteksi suhu, mendeteksi $\mathrm{pH}$ dan mendeteksi kadar gas belerang, cara merangkai dari komponen tersebut sehingga berjalan dengan baik, (b). pengkodean system. Pengkodean system ini dilakukan didalam software arduino IDE yang dimanakan agar protipe dapat berjalan dengan menggunakan program dan aplikasi yang sudah digunakan , (c). pengujian system. Pengujian system yang digunakan yaitu uji black box dan white box, uji ahli isi, uji ahli media, uji respon ke petani tambak yaitu pengujian keefektifan prototype dan uji kpraktisan prototype. dan (d). evaluasi system. Prototype akan di evaluasi oleh pemakain, selanjutnya jika user merasa setuju maka proses pembuatan dinyatakan selesai dan jika pemakai merasa ada yang perlu diperbaiki atau ditambahkan maka akan dikembangkan dipenelitian selanjutnya. .

\section{f. Kesimpulan}

Proses pengembangan prototype kapal pendeteksi kadar gas belerang dan suhu berbasis arduino akan diakhiri dengan proses penarikn kesimpulan dari cara pengembangan serta efektivitas perangkat. Hasil dari kesimpulan dapat digunakan untuk penelitian selanjutnya. 


\section{HASIL DAN PEMBAHASAN}

Berdasarkan dari uji coba keseluruhan pada hardware yang sudah dilakukan maka akan mendapatkan hasil keseluruhan dari penguji cobaan tersebut yaitu sebagai berikut :

Tabel 1 Pengujian Secara Keseluruhan

\begin{tabular}{|c|c|c|c|c|}
\hline Percobaan & Sample & $\begin{array}{c}\text { Dengan } \\
\text { Prototipe }\end{array}$ & $\begin{array}{c}\text { Tidak dengan } \\
\text { prototipe }\end{array}$ & Perbedaan \\
\hline \multirow{3}{*}{$\begin{array}{l}\text { Percobaan } \\
\text { suhu }\end{array}$} & Air dingin & $13,6 \stackrel{\circ}{C}$ & $10^{\circ} \mathrm{C}$ & 3,6 \\
\hline & Air biasa & 40,6 & 38 & 2,6 \\
\hline & Air hangat & 55,6 & 50 & 5,6 \\
\hline \multirow{5}{*}{$\begin{array}{c}\text { Percobaan } \\
\text { pH }\end{array}$} & Air aqua & $6,6 \div \mathrm{C}$ & 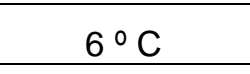 & 0,6 \\
\hline & Air jeruk & 4,42 & 4 & 0,24 \\
\hline & Cuka & 2,42 & 2 & 0,42 \\
\hline & Tetes mata & 10,42 & 11 & 1,42 \\
\hline & Air kapur sirih & 10,45 & 13 & 2,55 \\
\hline \multirow{3}{*}{$\begin{array}{c}\text { Percobaan } \\
\text { gas } \\
\text { belerang }\end{array}$} & Tanpa pembakaran & $17,7 \%$ & - & Rendah \\
\hline & Sedikit pembakaran & $30,6 \%$ & - & Sedang \\
\hline & Pembakaran penuh & $60,6 \%$ & - & Tinggi \\
\hline
\end{tabular}

Table diatas merupakan beberapa hasil pengujian yang sudah dilakukan. Hasil pengujian secara keseluruhan menyimpulkan bahwa perangkat dapat bekerja dengan baik dengan tingkat akurasi tingggi.

Selain uji coba pada hardware yang dilakukan, terdapat juga uji coba terhadap responden yang dilakukan pada petani tambak, beberapa ahli media dan ahli isi secara keseluruhan, yang dimana pada uji respon ini peneliti diberikan angket yang beberapa pernyataan terhadap prototipe. Berikut merupakan hasil dari uji respon secara keseluruhan yaitu berikul :

Tabel 2 Pengujian Secara Keseluruhan

\begin{tabular}{|c|c|c|}
\hline Uji Responden & Hasil & Keterangan \\
\hline Keefektifan & $100 \%$ & Efektif \\
\hline Kepraktisan & $96 \%$ & Praktis \\
\hline Ahli isi & $89,99 \%$ & Layak Digunakan \\
\hline Ahli media & $93,33 \%$ & Layak Digunakan \\
\hline
\end{tabular}

Berdasarkan hasil pengujian yang sudah dilakukan maka keseluruhan proses pengujian telah selesai dilakukan dan semua proses berhasil dengan demikian bahwa pengembangan prototipe pendeteksi kadar gas belerang dan suhu berbasis arduino ini dapat dikategorikan layak untuk digunakan, efektif dan sangat praktis. Dari hasl uji coba yang sudah diujikan maka terdapat beberapa kendala dalam pembuatan dari prototipe tersebut yaitu sebagai berikut :

A. Pengembangan prototipe pendeteksi kadar gas belerang dan suhu berbasis arduino dikembangan menggunakan beberapa komponen seperti sensor (suhu,gas, $\mathrm{pH}$ ), RTC, remote control, NRF dan data logger yang digunakan sebagai penyimpan data. Terdapat 2 mode dalam prototipe ini yaitu mode remote control dan kapal $R C$, mode remote control adalah mode dimana perangkat prototipe hanya berfungsi sebagai penggarah kapal saat kapal mulai dijalankan. Sedangkan mode kapal $R C$ yaitu mode yang digunakan untuk menjalankan aksinya yang dimana akan mulai mendeteksi sensor-sensor yang dibawanya.

B. Kendala pada saat pembuatan prototipe, disini juga terdapat kekurang pada prototipe ini yaitu kurangnya pendeteksian kedalama pada air danau. Menurut jurnal (Ahmad Muhtadi,2017) [10] pada danau-danau yang terbentuk secara vulkasnis, suhu di dasar tidak selalu lebih rendah dari pada suhu dipermukaan, sebab itu tergantung pada kedalaman yang dimiliki oleh setiap danau. Jadi bisa saja pada kedalaman $400 \mathrm{~m}$ suhu mengalami kenaikan hingga mendekati suhu permukaan.Kekurang juga terdapat pada memory penyimpanan data yang dimana pada memory yang menghasilkan data berupa text masih terlalu simple dan mesti ditambahkan lagi fitur grafik 
atau table agar bisa lebih mudah dalam melihat data yang sudah terdeteksi. Selain pada memory kekurangan juga terdapat pada frekuensi yang terdapat pada sinyal remote ke kapal yang dimana pada saat uji coba hanya dengan jarak 35meter, kekurangannya disini belum diuji cobakannya dengan jarak yang lebih jauh lagi dan keterbatasan radio komunikasi yang digunakan pada prototipe tersebut. Selain itu, prototipe ini hanya baru diuji cobakan pada arus air yang tenang dan air sungai yang sedikit surut jadi kekurang yang terdapat pada uji coba prototipe yang dimana pada prototipe yang dibuat belum bisa dioperasikan kedalam situasi arus air yang deras dan dalam cuaca yang sedikit ekstrem.

\section{SIMPULAN DAN SARAN}

Berdasarkan hasil observasi lapangan, wawancara, desain, pengembangan, pengujian dan evaluasi pengembangan prototipe kapal pendeteksi kadar gas belerang dan suhu berbasis arduino dapat diambil kesimpulan sebagai berikut.

a. Pengembangan prototipe prototipe kapal pendeteksi kadar gas belerang dan suhu berbasis arduino dikembangan menggunakan beberapa komponen seperti sensor (suhu,gas, $\mathrm{pH}$ ), NRF, joystick, driver motor DC, RTC. Data Logger yang digunakan adalah untuk menyimpan hasil pendeteksian pada setiap sensor. Terdapat 2 mode dalam prototipe ini yaitu mode remote control dan kapal RC, mode remote control adalah mode dimana perangkat prototipe hanya berfungsi sebagai penggarah kapal saat kapal mulai dijalankan. Sedangkan mode kapal $R C$ yaitu mode yang digunakan untuk menjalankan aksinya yang dimana akan mulai mendeteksi sensor-sensor yang dibawanya.Prototipe pendeteksi kadar gas belerang dan suhu ini menggunakan teknologi loT, dikarenakan prinsip tujuan utama dari loT sebagai sarana yang memudahkan untuk pengawasa. pemantauan dan pengendalaian barang fisik maka konsep loT sangat memungkinkan untuk digunakan hampir pada seluruh kegiatan sehari-hari.

b. Pengujian prototipe kapal pendeteksi kadar gas belerang dan suhu berbasis arduino mendapat respon yang sangat baik dari para petani tambak dan para uji ahli media dan juga uji ahli isi dilihat dari hasil pengujian serta antuiasme penggunaan prototipe. Jenis pengujian yang dilakukan adalah pengujian efektivitas, kepraktisan, uji ahli isi dan uji ahli media. Hasil dari pengujian tersebut didapatkan hasil bahwa pengguna menyatakan bahwa hasil pengujian efektivitas mendapatkan presentase sebesar $100 \%$, selain pengujian efektivitas dilakukan juga pengujian kepraktisan dari prototipe didapatkan hasil bahwa $96 \%$ petani tambak merasakan bahwa prototipe kapal pendeteksi kadar gas belerang dan suhu berbasi arduino sangat praktis untuk digunakan, selain itu pengujian prototipe kapal pendeteksi kadar gas belerang dan suhu berbasi arduino melakukan uji ahli media yang dimana peneliti menggunakan 2 orang untuk melakukan uji ahli media dengan hasil keseluruhan diperoleh $93,33 \%$ dinyatakan prototipe layak untuk digunakan dan pengujian terakhir yaitu dengan pengujian ahli isi yang melibatkan 2 orang ahli isi dengan hasil keseluruhan diperoleh $89,99 \%$ dinyatakan prototipe layak untuk digunakan.

Berdasarkan hasil penelitian yang sudah dipaparkan sebelumnya, terdapat beberapa saran untuk peneliti yang melakukan penelitian selanjutnya yaitu sebagai berikut :

1. Untuk penelitian selanjutnya dapat menambahkan sensor kedalaman agar bisa mendeteksi kedalaman air pada saat mendeteksi keadaan suhu, gas dan $\mathrm{pH}$ sehingga data yang didapatkan akan lebih akurat lagi.

2. Untuk peneliti selanjutnya disarankan untuk menambahkan LCD pada prototipe agar masyarakat yang menggunakan prototipe tersebut dapat melihat secara langsung data yang diperoleh.

3. Penelitian selanjutnya disarankan untuk mengembangkan lagi pendeteksi kadar gas belerang dan suhu berbasis arduino ini agar mendapatkan hasil yang lebih maksimal dan berguna bagi masyarakat petani tambak nantinya.

4. Penelitian selanjutnya disarankan untuk mengkaji lebih lanjut terhadap posisi sensor yang digunakan dan sensitifitasnya dalam mengukur kadar gas belerang.

5. Peneliti selanjutnya disarankan agar bisa melakukan uji coba jarak remote ke kapal dalam jarak yang lebih jauh lagi dari 35 meter yang sudah diuji cobakan sebelumnya.

6. Peneliti selanjutnya disarankan agar bisa mengimplemasikan kembali data yang disimpan pada memory card agar tampilan data yang digunakan nantinya bisa berupa grafik atau table untuk memudahkan petani tambak dalam membaca data yang suda terdeteksi.

7. Peneliti selanjutnya disarankan agar bisa nantinya mendesain prototipe tersebut lebih besar lagi agar penempatan pada komponen-komponen yang digunakan lebih beraturan lagi. 


\section{DAFTAR PUSTAKA}

[1] SURYONO, T., S. NOMOSATRYO dan E. MULYANA 2008. Tingkat kesuburan Danau-Danau di Sumatera Barat dan Bali. Limnotek XV pp.1-2

[2] S Garno, Y. S. dan T. A. Adibroto. 1999. "Prosiding Semiloka Nasional Pengelolaan dan Pemanfaatan Danau dan Waduk". PPLH-LP , IPB Ditjen Bangda Depdagri, Ditjen Pengairan, Kantor Meneg. LH. XVII

[3] Ghufran, M. K. (2001). Usaha Pembesaran Ikan Kerapu di Tambak. Yogyakarta: KANISIUS..

[4] Ghufran, M. K. (2010). Budidaya Ikan kerapu Batik. Jakarta: Akademia

[5] Suryadi HS dan Bunawan, 1996 Pengantar Implementasi Dan Pemeliharaan Sistem Informasi. Penerbit Gunadarma.

[6] Muhammad Syahwil. 2013. Panduan Mudah Simulasi dan Praktik Mikrokontroler Arduino,, Yogyakarta : ANDI.

[7] Riyan Kurniawan Putra (2017). Rancang Bangun Pendeteksi Gas Belerang Dan Kekeruhan Air Untuk Pemberian Pakan Ikan Otomatis.Penulis. JudulTesis/ Disertasi. Tesis/ Disertasi. Kota\&Nama Kampus; Tahun.

[8] Lukman, Sutrisno, \& Agus Hamdani. (2013). Pengamatan Pola Stratifikasi Di Danau Maninjau Sebagai Potensi Tubo Belerang. Pusat Penelitian Limnologi,LIPI.

[9] Saputra, Yoga Eka. 2014 Rancang Bangun Wireless Sensor Network Untuk Monitoring Pencemaran Air Sungai Menggunakan Topologi Mesh Network. Jurnal CONES, Volume III, No.2 : Surabaya.

[10] Rangkuti, Ahmad Muhtadi, Muhammad Reza Cordova, Ani Rahmawati, Yulma, and Hasan Eldin Adimu, 2017. Ekosistem Pesisir Pantai Dan Laut Indonesia. Edited by Sri Budi Hastuti and Restu Darmayani, Jakarta: Bumi Aksara. 